\section{John Ginn}

is Vice President, Consulting,

at CACI, where he leads

CACI's client work on CRM and marketing strategy and implementation. Before joining CACI he was a Director at Sophron.

\section{Merlin Stone}

is a leading author and advisor on CRM programme management and implementation. He is Visiting Professor of Marketing at a number of universities, including Oxford Brookes.

\section{Yuksel Ekinci}

is Professor of Marketing at the Business School in Oxford Brookes University. His research interests include customer satisfaction, service quality and services branding.

Keywords: customer retention, customer loyalty, personalization, customer complaint management

The credit crunch has caused companies to focus intensively on customer retention

\section{Merlin Stone}

Rose Cottage

Ship Knapp

Morcombelake

Dorset DT6 6EW, UK

Tel: +447968271937

E-mail: merlin@merlin-stone.com

\section{Opinion Piece}

\section{Customer retention management in the recession}

\author{
John Ginn, Merlin Stone and Yuksel Ekinci \\ Date Received: 21st July, 2010
}

\begin{abstract}
The purpose of this article is to explore customer retention strategies and tactics implemented by firms in recession. Our investigations show just how big a challenge many organizations face in their ability to manage customer retention effectively. While leading organizations have embedded real-time customer life cycle management, developed accurate early warning systems, price elasticity models and 'deal calculators', the organizations we spoke to have only gone as far as calculating the value at risk and building simple predictive models.

Journal of Direct, Data and Digital Marketing Practice (2010) 12, 115-127. doi:10.1057/dddmp.2010.27
\end{abstract}

\section{Introduction}

The credit crunch has destabilized the marketer's world. In the next few years, many customers will be forced to change how they spend their money. After years of boom, in which many companies found it easy to achieve steady growth in sales and in their customer bases, they are facing a new reality. Customer retention is the new focus area for marketers and is an area where advanced techniques and strategies are being rapidly adopted. It has also become an important area of focus in the academic literature, as our review below demonstrates. The purpose of this investigation is to explore customer retention strategies and tactics implemented by firms in recession.

\section{Customer retention management}

In our inquiries, customer retention is defined as customers' declared continuation of a business relationship with the firm. Customer retention management is defined as development and implementation of a customer information-based customer-centric marketing strategy for managing and nurturing a company's interactions with specific customers or groups.

Customer retention has been shown to be a primary goal in firms that practice relationship marketing because customer retention yields several economic values. ${ }^{1}$ In their study, Reichheld and Sasser ${ }^{2}$ reported that a 5 per cent increase in customer retention increases a firm's 


\section{Customer satisfaction measure are not sufficient to predict retention, but they help}

\section{Straightforward strategies and tactics improve retention, particularly for loyal and for valuable customers}

\author{
Where customer \\ attrition is related \\ to poor service, the
}

profits at a range between 25 and 85 per cent. Acording to Gronroos, the cost of customer retention is much lower compared to the cost of acquiring a new customer. ${ }^{3}$ In fact, it is estimated that the cost of acquiring a new customer is six times more expensive than retaining an existing one. ${ }^{4}$ Furthermore, retained customers may purchase in higher volumes than newly acquired customers. Finally, retained customers are more likely to recommend others to become customers of the firm. ${ }^{2}$

As customer retention is a critical issue, a number of organizational processes are used to monitor its performance and guide improvement efforts. Although there is no consensus as to the best means of gauging customer retentions, some of the practices include customer measurement processes, customer retention planning processes, quality assurance processes, win-back processes and complaints handling processes. ${ }^{1}$ Customer satisfaction measurements are typically obtained through customer surveys and customer metrics (eg customer satisfaction index, customer expectation index, customer value analysis, brand preference analysis, repurchase and recommend intention measures, share-of-wallet analysis, trend in spending) that contain measures of satisfaction, repurchase intention, and word-of-mouth intention. Many managers believe that these measures serve as leading predictors of customer loyalty and the firm's future market share. ${ }^{5}$ Past studies state that a single measure (eg intention to recommend) does not suffice as a single predictor of customer's future loyalty behaviour. For instance, Newman and Werbe ${ }^{6}$ reported that satisfaction explained only 6 or 7 per cent of the variance in retention. Recent studies show that in addition to customer satisfaction, overall attitude towards a firm should be used to predict loyalty intentions. ${ }^{7,8}$ Keiningham et al. suggest that multiple indicators should be used for better predicting customer retention. ${ }^{5}$

The central idea of customer retention management processes is that profitable customer retention can be achieved through straightforward marketing strategies and tactics, using data on customers' interactions with the company and value to the company. Although there has been little research specifically into the development and content of customer retention plans, some investigators and commentators have reported a number of customer-oriented planning tactics and questions. These include what should be the relative weight attached to customer retention budgets, how to define and measure customer retention, how to segment customers for customer retention efforts and what strategies to employ to recover at risk or churned customers. ${ }^{1}$ Considerable attention has also been paid to assessing the role and effectiveness of retention strategies and tactics towards valued, at-risk or churned customers. For example, a number of studies have examined the contribution of relationship marketing instruments such as customer loyalty and customer marketing programmes. ${ }^{9}$

An important element of retention management is managing service failures. The complaint handling process refers to the strategies and tactics that firms use to resolve and learn from service failures in order to establish the firm's credibility in the eyes of the customer. ${ }^{10}$ Developing an effective complaint management has been the subject of 


\section{perceived justice of service recovery actions has a big effect on retention}

\section{Communication, customer service and support all help companies keep their customers}

some debate. Bell and Zemke ${ }^{11}$ proposed five components of effective service recovery and complaint handling: apology, urgent reinstatement, empathy, symbolic atonement and follow-up. Recent research on consumer complaining has focused on the implementation and effectiveness of complaint handling process. ${ }^{12,13}$ Building upon the foundations of equity theory, the literature in social psychology and organizational behaviour, perceived justice is seen as an aggregate construct by which consumers assess the fairness of a service recovery situation, or dissatisfaction decision based on three dimensions: procedural justice (the perceived fairness of the resolution procedures), interactional justice (the perceived fairness of the interpersonal communications and behaviour) and distributive justice (the perceived equity of the outcome). Typically, procedural justice is operationalized as the delay in processing the complaint, process control, accessibility, timing/speed and flexibility to adapt to the customer's recovery needs. Interactional justice refers to the fairness of the interpersonal treatment that customers receive during the complaint handling process, including elements such as courtesy and politeness exhibited by employees, empathy, effort observed in resolving the situation, and the firm's willingness to provide an explanation as to why the failure occurred. Finally, distributive justice focuses on the perceived fairness of the tangible outcome of the decision. In effect, distributive justice is concerned with cost-benefit analysis and the level and nature of apologies and compensations to arrive at a decision of whether or not the perceived outcome is held to be deserved. ${ }^{12}$

\section{Customer retention strategies and tactics}

Past studies have identified ad hoc, practical and structured strategies and tactics for retaining customers. Building a good relationship with current customers and continuously creating a relational value seems to be the best way to keep customers loyal. This can be done in different ways, such as by contacting the customer periodically to ensure that the service provided them is satisfactory. According to Blattberg and Deighton, ${ }^{14}$ these tactics should be given the same attention and focus that sales calls receive, because in effect they are sales calls for repeat business. Customer service and support is also essential for building the relationship of the firm with the customer. Kelley et al. ${ }^{15}$ suggest that a better customer service ensures higher customer loyalty. This will help in understanding the customer preferences, queries and requirements in a better manner, and hence reduce the time taken to solve the problems faced by customers.

Loyalty programmes are relationship marketing instruments used for improving customer retention. The success of loyalty programmes is achieved mainly by developing a strong proposition that supports loyalty management, by gathering and analysing customer data, and acting accordingly. Customer retention data analysis focuses mainly on:

(a) What are the expectations of customers?

(b) What actions can be taken to meet them? 


\section{Predictive modeling of attrition is an essential element of retention management}

(c) What is the growth opportunity with existing customers?

(d) Who are the valued customers who should receive a better treatment, and what treatments are they likely to respond to?

(e) How do customer interactions affect satisfaction and loyalty?

(f) How can interactions be improved?

(g) What strategies are required to take customers to higher loyalty levels?

Predictive modelling is a statistical technique that can be used for managing customer retention. It can be deployed using advanced qualitative and quantitative methods (eg neural networks, regression techniques, logical algorithms, decision trees) to score each and every detail about a customer so as to give an estimate about his/her probability of stay or churn over a specified period of time. Graphical, tabular and other visual tools can also provide quick insight into the factors that have led to customer churn, so that the churn can be reduced as soon as possible. Predictive modelling can also be combined with marketing metrics, such as profitability per customer and longevity of each customer, so as to design a tailor-made retention strategy whenever a churn probability appears. Retention strategies can be personalized and vary on the basis of, for example, customer value. $^{16}$

Personalization and customization are effective strategies for improving customer experiences and customer retention. ${ }^{17}$

Customization aims to foster higher customer loyalty and can result in enhanced returns on marketing investments. Personalization also creates the perception of increased choice by enabling a quick focus on what the customer really wants. ${ }^{18}$ In addition to personalization, building loyalty among customers becomes an easy task if the firm has a loyal labour force. This is because customer strategy is often implemented through frontline employees (eg sales, customer service, technical support). Over a period of time, customers develop bonding with employees, which in turn improves customer satisfaction and loyalty. ${ }^{19}$ The frontline employees need to be recruited, trained and retained with this requirement in mind. Training employees to provide a specific kind of service, empowering them to take decisions at their own level, letting them know at all levels the importance of and the results of having higher loyalty through examples, lets employees relate more to the organization and in turn with the customer too. ${ }^{20}$

\section{Methodology}

To explore how companies are managing customer retention during the recession, a qualitative study was conducted. A questionnaire with open-ended questions was developed, based on the following themes:

- Respondents' general approach to identifying customers at risk of leaving, including whether they are expected to switch to a competitor or leave the category 
- The use of externally sourced customer data in predicting attrition of individual customers

- Integration of retention activity across channels

- The effect of customer communication on retention, especially over the customer life cycle

- The issue of false positives and the use of control groups to test retention activity

- Use of real-time marketing techniques

- How retention levels have changed since the onset of the recession

- How companies have changed their retention offers as a result of the recession

The questionnaire was e-mailed to 80 large companies operating in a number of sectors, including financial services, telecommunications, oil, property, insurance etc. They were all well-known national brands. The companies were chosen on the basis of their existing close contacts with CACI or Professor Stone, and therefore are a biased set, as these would be companies most interested in customer database-derived retention. Of these, 20 valid questionnaires were obtained. Almost 50 per cent of the responses (four banks, five insurers) were from the financial services sector, mainly because of the strength of this sector among our contacts. The other companies were from telecommunications (2), oil (1), media/entertainment (3), property (1), travel (1), utilities (2), service/insurance contracts (1).

\section{Findings}

This study was qualitative, and therefore we present the findings as summaries, with verbatim quotes from the responses as examples to illustrate them.

\section{In a recession, customers generally seek to obtain better value, rather than to move between companies}

\section{The firm's customer value proposition}

For most of these respondents, the recession had caused customers to search for more value, but generally not to switch more. Exit from category had increased in very few cases. As a result, companies were focusing strongly on developing better value and reinforcing this through clear and appropriate customer communications. Across the board, customers appeared to be interacting ever more frequently with organizations in order to ensure that they are getting the best-possible value in products and services. Companies were becoming more sophisticated at predicting customer behaviour and initiating communications and offers that best reflected value for individual customers, confirming the points raised in our review of literature on retention strategies and tactics. We suggest that as the customer search for value intensifies, companies in many sectors that have the capability to optimize communications in real-time or near real-time will be best placed to retain and grow market share.

'We've noticed a trend whereby customers are more price-focused at renewal and have had to work harder to keep the retention levels 


\section{Real time marketing aids customization and rentention, but is rarely used}

the same by offering these people more incentives where viable. Our approach in addition to this has changed to become more intelligent - we now segment our base by value and likelihood to leave and focus our efforts and incentives accordingly on the customers we feel have most value and we are likely to be able to save. Incentives are customised and targeted to customer groups so that they receive relevant offers'. (Financial services company)

'We've recently stepped up the insight used into producing more relevant incentives for customer groups to help try and retain them. The value of the offers for some of these groups has also gone up and some of the offers are closer to cash than previous'. (Financial services company)

'Retention offers have changed in line with the more aggressive acquisition offers that we have in the market. Clearly we have to ensure that customers receive as good, if not better offers than new acquisitions, otherwise churn would go through the ceiling. Value from our combined offerings has helped customers to get more value from their relationship with us'. (Media company)

'Yes - we have much richer discounts available for agents to use and a very competitive set of competitor match products which can be used by the specialist staff, as appropriate. We have also invested heavily in up-skilling agents and improving our systems, rather than just enriching offers'. (Contract marketing company)

\section{Applications of real-time marketing tactics to customer retention}

The most advanced form of using customer data to change propositions to meet customer needs better and thus retain them more effectively is real-time marketing, in which data given during an interaction are used to change which proposition is suggested to the customer.

However, the use of real-time marketing was rare, with two exceptions - one telecommunication company and one media company - although utilities companies have plans in this area. This result is surprising. In our experience as consultants, for many organizations, real-time marketing produces good results, in terms of up-sell, cross-sell, retention and customer satisfaction. It also reduces costs in other areas, typically the batch marketing areas such as direct mail and outbound telemarketing.

'Yes, we use real-time marketing techniques in our channels and these include retention offers. We use a specialised commercial software package linked to our front-end systems'. (Telecommunications company)

'The call centres use real-time marketing techniques taking batch data feeding from our marketing data marts and utilising 
information from real-time interactions and logic built within our specialised commercial software package to deliver appropriate

Next-best-actions for the customer'. (Media company)

\section{Implementation of customer retention planning}

Some companies rely on predictive models for estimating customer churn and adjusting marketing accordingly. External data were occasionally used for high-level modelling, for one or two companies for detailed scoring, and by the two utilities it was used comprehensively for attrition modelling. Credit score data were used primarily to determine whether a customer should be retained. One financial services company used data on whether a customer had accessed aggregator sites as an indicator of possible attrition. The respondent that was a member of the Nectar loyalty scheme used its data intensively for attrition modelling and prediction.

'We have a steady steam of external data that we use from third parties to help us build models to predict loss. We do have access and use credit information, but are aware that different debts are looked at in different ways eg people are more likely to pay our bill than an energy bill. The external data is critical to us for modelling new prospects and areas. We will use internal customer data when it is available ie when they are with us'. (Utility company)

\section{Financial services companies are advanced users of predictive attrition modeling to support their retention management}

Most financial services companies had a well-established approach to predicting attrition using predictions of the propensity of customers to lapse, but this varied according to whether the product was fixed term. Only one had a more basic approach, sending retention communications to all customers nearing product term. Whether attrition modelling covered leaving the category or switching varied by product specialism; customers cannot choose whether to insure their cars, but can decide to cash their savings. However, most companies did not make this distinction.

'We have built an attrition model based on the profile of customers who have left us recently. This model has been applied to the remaining customer base to identify those in the high risk category. Behaviour is a key component of this model — we have found variables such as duration of the relationship with us and the number of products they've held with us to be predictive of whether they're likely to leave. We are planning to test a series of initiatives encouraging these members to switch to a more suitable product'. (Financial services company)

Retention across the life cycle was managed well by some, and across channels by slightly more respondents. Many of the companies used control groups to identify whether their overall retention activity was effective. However, several companies had not done the detailed work to identify the effect of different types and frequencies of communication on retention. This means that they could not optimize 
communication between channels or over the customer life cycle. We regard this as a huge opportunity, especially given the availability of the services, data and software to allow companies to optimize in this way, and the strong positive return on investment achieved by those who have.

'We predict and track retention by channel eg online or offline and can overlay media to this mix. At the current time we do not, in general, differentiate our retention activity by media/channel. We have however, developed a number of incentives targeted at key value segments and channel is implicit in this segmentation. We have also provided different incentives based on payment type annual or DD as this is such a key predictor of retention at renewal'. (Financial services company)

'There are different approaches to retention depending on channel of acquisition. For example, the offline originators with high likelihood to lapse are telephoned in addition to being mailed with offers, in an attempt to retain them. Online customers are more likely to be e-mailed. All customers are also given a value score in addition to a propensity to lapse score so that the decision to retain them can be based on likelihood to lapse and value to us if retained (two axes). Retention is predicted by channel of acquisition'. (Financial services company)

'Customer management is well integrated through central data stores and software platforms. The channel by which we acquire customers is a key determinant of their quality and their subsequent likelihood to churn. Churn by channel is predicted. Our challenge is to manage a more complex sales message due to the varied product offerings that we provide. So face to face channels are useful for getting the point across, but retention of these customers becomes complex'. (Media company)

'We predict retention by both channel of acquisition and preferred channel. We see a wide range of retention according to acquisition eg customers from the aggregator uSwitch are more likely to leave us; they are generally looking for a good deal and will constantly get emails from uSwitch after they have joined us'. (Utility company)

"Customers are divided into "Nursery" (first 12 months) and "Existing" (subsequent lifetime) and are also sub-segmented within these categories to include consideration of tenure. "Nursery" customers tend to have a much more controlled customer journey and more carefully orchestrated contact. Existing customers are more driven by events'. (Utility company)

Most non-financial companies had mature approaches, in the sense that they had a retention management process that had been in place for several years, producing well-understood metrics, although there was a 
broad range of practice, accounted for mainly by the type of industry, which determines the business model for customer retention.

Companies with a mainly direct marketing-based model, such as telecommunications, financial services and one of the media companies, tended to follow the most advanced practice.

'Data fundamentally drives this activity. While credit scoring would be a valuable approach in limiting our exposure to churning customers, we don't currently use it. A number of activities have been identified that help us view customers who are becoming "At Risk", changing methods of payment, reducing the level of commitment that the customer has with us, refusal to take one of our additional "value add" subscription products that would normally provide an increased element of customer "stickability". Customers that leave are not profiled to a great extent. We want them back and will communicate with them accordingly. We do however look at their previous activity as a customer which helps provide insight into their previous levels of engagement with the company'. (Media company)

'The starting point is to identify the reasons for churn among our base and understand what data is available to help us address this. For example before the credit crunch 10 per cent of the population moved house each year. Ensuring that we captured the move and responded is critical, as people fix their purchasing routines within 20 days of moving. All our customers are allocated to segments and the segments are tracked. Change in the behaviour of customers creates predefined "Trigger" events determined by transactional or other events'. (Oil company)

\section{Understanding the relationship between service failure and churn is a key part of retention management}

\section{Customer complaint handling and churn process}

These processes relate to how companies deal with service failure and actual churn.

'We profile customers who have left us and compare the characteristics of these customers to our base. These characteristics, which include usage and change in usage over a number of months, have been incorporated into a propensity model, which is used to score the base for churn risk'. (Telecommunications company)

'We profile all of our base throughout their tenure and actively track over 1600 cohorts. We also undertake market research into those who leave, as well as collecting cancellation codes within call centres, giving us a 3D view of where a customer is going, why and how we were informed. We have analysed churn extensively and the key identifiers of churn are as follows: payment method (DD best, cheque worst), tenure (particularly customers in their first year), sale method (channel used, special 


\author{
The ideas of retention \\ management are \\ generally well \\ understood, but the \\ remedies for attrition \\ used are mostly basic
}

offer, etc); service call out experience (good/bad/none). These factors are so strong and predictive that geo-demographic data, or even financial commitment data has little uplift'. (Service contract marketer)

'Clearly if we can understand which customers have left us, we can contact them to understand why they left. In our industry, the high price followed by the credit crunch recession has made customers not just price sensitive but has changed the structure of the market in so far as consumers have fundamentally changed their behaviour to the category. This means that ensuring value is seen and felt is critical'. (Oil company)

\section{Conclusions}

On the basis of this, admittedly small, sample, the recession seems to be causing some changes to customer management policy, but not enormous ones. It is acting like any other significant change in the marketing environment, causing some companies to focus slightly more on retention. In most sectors, the recession has not greatly increased the amount of switching between suppliers, and in some not at all, but it has increased customers' search for value.

Broadly speaking, the companies we have talked to understand the issues raised in the literature review - why customers leave and what can be done about it, and how to use data to understand this process. Some companies are therefore providing products with improved value to achieve greater retention, and some are drawing customers' attention to their better-value offers, although generally not using the latest techniques in real-time marketing. On the one hand, most companies have made good progress in multichannel management of retention, but have some way to go. On the other hand, there seems to be a lack of attention paid to intra-organizational factors, particularly how attrition problems with one product may affect another. With a few exceptions, there is lack of use of real-time marketing - which is ideal for ensuring that customers get the right value proposition or product. Most of these companies have not invested in the optimization and real-time marketing techniques, systems and processes that could be used to ensure that their customers get the value they are increasingly seeking in the recession. A related issue is that the use of data derived from customers' explorations on the web, for example of different value propositions, seems rare.

Most of these companies have limited understanding of how different communication patterns affect retention, at different stages of the customer life cycle, but this varies by sector, with the strongest understanding being by those companies that have, for some years, had a well-established retention model. Externally sourced data are used by some companies to help predict attrition, but the extent of use varies by sector. In some sectors, creditworthiness is an important focus, and external data are useful here. 


\section{Optimizing communications still represents a real opportunity for most companies to improve their retention management}

\section{Managerial implications}

In a time of sudden and deep recession, companies were challenged by sudden changes in their marketing environment. They were confronted with the question - am I doing all I should to achieve my customer management and eventually profitability targets? For many companies, there is, in our view, a significant opportunity to improve retention by optimizing communication across different channels over time. Realtime marketing, in particular the use of a set of analytically derived 'next-best-actions' in all contact channels, designed to encourage customers to achieve their value objectives in particular ways, seems tailor-made for this situation. Using this approach methodically allows companies to discover which value-based propositions work best for particular customers. Yet, although our respondents had identified that customers were seeking better value, they had, with a few exceptions, not invested in the analysis, systems and processes needed to ensure that customers get the value that they seek.

\section{References}

1. Ang, L. and Buttle, F. (2006) 'Customer retention management processes: A quantitative study', European Journal of Marketing, Vol. 40, No. 1, pp. 83-99.

2. Reicheld, F.F. and Sasser Jr, W.E. (1990) 'Zero defections: Quality comes to service', Harvard Business Review, Vol. 68, No. 5, pp. 105-111.

3. Gronroos, C. (1994) 'From marketing mix to relationship marketing — towards a paradigm shift in marketing', Journal of Business and Industrial Marketing, Vol. 2, No. 1, pp. 322-339.

4. Jobber, D. (2004) Principles and Practice of Marketing, 4th Edition, McGraw-Hill, Berkshire.

5. Keiningham, T.L., Cooil, B., Aksoy, L., Andreassen, T.W. and Weiner, J. (2007) 'The value of different customer satisfaction and loyalty metrics in predicting customer retention, recommendation, and share-of-wallet', Managing Service Quality, Vol. 17, No. 4, pp. 361-384.

6. Newman, J.W. and Warbe, R.A. (1973) 'Multivariate analysis of brand loyalty for major household appliances', Journal of Marketing, Vol. 10, pp. 404-409.

7. Ekinci, Y., Dawes, P. and Massey, G. (2008) 'A model of consumer satisfaction for hospitality services', European Journal of Marketing, Vol. 42, No. 1/2, pp. 35-68.

8. Guo, L., Xiao, J.J. and Tang, C. (2009) 'Understanding the psychological process underlying customer satisfaction and retention in a relational service', Journal of Business Research, Vol. 62, pp. 1152-1159.

9. Dowling, G. and Uncles, M. (1997) 'Do customer loyalty programmes really work?' Sloan Management Review, Vol. 38, No. 4, pp. 71-82.

10. Hart, C.W.L., Heskett, J.L. and Sasser, W.E. (1990) 'The profitable art of service recovery', Harvard Business Review, Vol. 68, No. 4, pp. 148-156.

11. Bell, C.R. and Zemke, R. (1987) 'Service breakdown: The road to recovery', Management Review, Vol. 76, No. 10, pp. 32-35.

12. Blodgett, J.G., Hill, D.J. and Tax, S.S. (1997) 'The effects of distributive, procedural, and interactional justice on postcomplaint behaviour', Journal of Retailing, Vol. 73, No. 2, pp. 185-210.

13. Tax, S.S., Brown, S.W. and Chandrashekaran, M. (1998) 'Customer evaluation of service complaint experiences', Journal of Marketing, Vol. 62(April), pp. 60-76.

14. Blattberg, R.C. and Deighton, J. (1996) 'Manage marketing by the customer equity test', Harvard Business Review, Vol. 74, No. 4, pp. 136-144.

15. Kelley, S.W., Hoffman, D.K. and Davis, M.A. (1993) 'A typology of retail failures and recoveries', Journal of Retailing, Vol. 69, No. 4, pp. 429-452. 
16. Pasloe, S. (2010) 'Impacts of customer relationship management on customer loyalty in the UK telecommunications industryUnpublished MBA Dissertation, Oxford Brookes University, Oxford.

17. Berry, L.L. (1995) 'Relationship marketing of services — growing interest, emerging perspectives', Journal of the Academy of Marketing Services, Vol. 23, No. 4, pp. 236-245.

18. Shostak, G.L. (1987) 'Breaking free from product marketing', Journal of Marketing, Vol. 41(April), pp. 73-80.

19. Ekinci, Y. and Dawes, P. (2009) 'The impact of frontline employee personality on consumer satisfaction', The Service Industries Journal, Vol. 29, No. 4, pp. 503-521.

20. Fisk, R.P., Grove, S.J. and John, J. (2000) Interactive Services Marketing, Houghton Mifflin, NY.

\section{Appendix}

\section{Questionnaire}

1. What general approach do you use to identify customers at risk of leaving you or substantially reducing their commitment to you? Do you profile customers who have left and apply this profile to your remaining customers? If so, does this profiling take into account their previous behaviour (eg usage) and if so, over what period?

2. For customers who are predicted to leave, do you predict whether a customer is likely to leave your category entirely or switch to a competitor? If so, what approach do you use to make this prediction?

3. To what extent do you use externally sourced customer data in predicting whether customers are likely to leave? Do these data include data on customers whose financial situation makes them likely to leave (eg because they have defaulted on credit to another supplier)? How critical are these external data to you, and why?

4. To what extent is your customer management integrated across different channels, and how? Does your customer retention vary much according to channel of acquisition? Do you predict retention by channel of acquisition and/or by the customer's preferred channel?

5. Have you identified the effect of how you communicate with customers on whether you retain them? If so, what is the effect?

6. How do you manage the risk of false positives (customers where attrition is predicted who are in fact unlikely to leave, but where your offer of a retention incentive might either stimulate attrition or be taken as a benefit by the customer with no change in their intentions)? Do you use control groups?

7. How much is retention affected by different activities that you undertake with customers during their life cycle? Do you divide your customer life cycle into different phases (eg early life, maturity) and manage customers differently at different stages. If so, what is the difference?

8. Do you use real-time marketing techniques in your contact centres or on the web so as to maximize retention? If so, how software, processes, data etc? 
9. Have your retention levels changed since the onset of the recession? If so, by how much? Have they changed more for customers of particular products or services, or for customers of particular value levels? Has your approach to retention management changed as the recession has deepened?

10. Have you changed how you manage your retention offers? Have you had to provide more valuable offers or provide additional services? 